\title{
Pregnant Women View Regarding Cesarean Section in Northwest Pakistan
}

\author{
Qudsia Qazi ${ }^{1 *}$, Zubaida Akhtar ${ }^{2}$, Kamran Khan ${ }^{3}$ and Amer Hayat Khan ${ }^{4}$
}

${ }^{1}$ Women and Children Teaching Hospital Bannu, KPK, Pakistan

${ }^{2}$ Gynae B ward, Khyber Teaching Hospital Peshawar, KPK, Pakistan

${ }^{3}$ Khalifa Gul-Nawaz Hospital, Bannu, KPK, Pakistan

${ }^{4}$ Clinical Pharmacy, School of Pharmaceutical Sciences, Universiti Sains Malaysia, Malaysia

\section{Abstract}

Objective: Cesarean Section (CS) is a commonly performed procedure for women, with almost a third of women in many developed countries experiencing when they give birth. CS is still being perceived as an abnormal means of delivery by many antenatal women in remote areas of Pakistan. Aim of the study is to determine the perceptions of antenatal clients in the North West of Pakistan on CS.

Materials and methods: A self-administered questionnaire based survey was designed. Subjects were enrolled from September 2009 to December 2009 in Women and Children Teaching Hospital Bannu, Pakistan. Pre-validated, self-developed questionnaire was used for study data. The data was fed to Statistical Package for Social Sciences (SPSS $16^{\circledR}$ ) to analyze and presented in a simple frequency table.

Results: Of 450 pregnant patients, 402 responded the questionnaire. Age of the respondents ranged between 16 and $44(27.21 \pm 4.04)$ years. Only $7(1.7 \%)$ viewed CS as feasible and elected to undergo CS. Seventy one $(17.6 \%)$ considered CS good in case of threat to their lives, whereas 195 (48.6\%) didn't accept CS in any circumstances. Only 35 (8.7\%) women viewed CS uncomfortable in context of cultural barrier and a curse for women.

Conclusion: Present study affirms previous suspicion that a significant proportion of antenatal clients are averse to $\mathrm{CS}$ and the negative cultural perception of the people to CS reinforced present aversion.

\section{Keywords: Cesarean section; Women; Perception}

\section{Introduction}

Caesarean section (CS) is a common operative surgical procedure worldwide [1] where fetus is delivered through an abdominal and uterine incision $[1,2]$. The indications can either be based on maternal or fetus associated complications. The proportion of women giving birth by CS has increased with time in all developed countries over the past several decades [3]. Moreover, the level of CS is well above the WHO (1985) mentioned 15\% mark for many of the countries and is still increasing.

In 1998, 21\% of Australian women gave birth by CS that increased to $30.9 \%$ by 2007 [4]. Same trend were observed in the USA where $31.1 \%$ of all births were carried by CS in 2006 which was once $20.7 \%$ in 1996 [5]. While the overall rate of cesarean birth is lower in the UK, accounting for almost 25\% of all births from 2007 to 2008, it has however increased by approximately 50\% from 1995-1996 [6]. Birth rates via CS vary considerably across Europe, ranging from 15\% in Norway and the Netherlands, $17 \%$ in Sweden and Finland and increasing to $37.8 \%$ in Italy [7].

The estimates for the CS rate in East Asia also show that it is well above the 15 percent mark. Even the rate of caesarean delivery in Pakistan was 20\%, whereas in Taiwan (China) it was 35.15 percent in 2007 [8]. The estimates of CS rates in India is 7.1 per cent in the year 1998 and there is 16.7 percent change in the rates annually in India, which is one of the highest among the countries.

The change in CS rate in the developing countries has been less dramatic during the same period. CS is still being perceived as an abnormal means of delivery by some women in the developing countries based on some factors like inadequate facilities and medicine [9]. Therefore the CS rate in some sub-Saharan African countries (like Burkina Faso and Niger) is as low as $2 \%$ [10]. The negative view and perception of CS by women in the developing countries has led to gross underutilization of the procedure compared to the large burden of obstetric morbidity requiring resolution by CS [11].

CS is often perceived to be safer than vaginal delivery for mothers and their infants, and has become increasingly common around the globe [12]. Awareness and acceptance for labor analgesia was relatively low among the prospective parturient. A higher level of education had a significant impact on the decisions regarding delivery [13].

The factors associated with caesarean section are age, parity, multiple pregnancy, maternal weight gain, and birth weight [14]. Including these factors, the caesarean section is justified under certain circumstances such as cephalo pelvic disproportion and contracted pelvis; dystocia due to soft parts; inadequate uterine forces, antepartum hemorrhage, pre-eclamptic toxaemia, eclampsia; fetal distress and prolapse of the cord, malpresentation; maternal distresses such as heart problems, bad obstetric history, habitual intrauterine death of the fetus and elderly primigravida. Except these demographic and medical reasons, patient's request and decision of physician also play a major role in increasing caesarean section rates [14]. Patients request the obstetricians to perform the caesarean section as it is less painful

*Corresponding author: Qudsia Qazi, Women and Children Teaching Hospital Bannu, KPK, Pakistan, Tel: 0092-928-621810; E-mail: qudsiakamran@gmail.com

Received January 02, 2013; Accepted February 03, 2013; Published February 10,2013

Citation: Qazi Q, Akhtar Z, Khan K, Khan AH (2013) Pregnant Women View Regarding Cesarean Section in Northwest Pakistan. Trop Med Surg1: 105. doi:10.4172/2329-9088.1000105

Copyright: (C) 2013 Qazi Q, et al. This is an open-access article distributed under the terms of the Creative Commons Attribution License, which permits unrestricted use, distribution, and reproduction in any medium, provided the original author and source are credited. 
and consumes less time. Physicians prioritize CS due to convenient and quick handling than attending a normal vaginal delivery [15]

Due to limited data on the perceptions of women in the country about CS, and their views about women who had the procedure have not been explored. Therefore, present study aims at the determination of the perceptions of women in the northwest area of Pakistan on CS and their views about other women who have had CS in the past.

\section{Materials and Methods}

\section{Study design and location}

Study was based on a descriptive review conducted to evaluate the perception towards CS. It was carried out from September 2009 to December 2009 at Gynae unit of Women and Children Teaching Hospital Bannu, Pakistan. District Bannu is centre in south part of Khyber Pakhtun-Khawa (North West Frontier) province of Pakistan with 942,230 population and male to female ratio of 1:1.08 [16]. Women and Children Teaching Hospital Bannu is secondary level referral hospital. Gynae unit of the hospital is largest in the area where emergency obstetric surgery is performed. Annually, 7000 to 8000 patients are being attended in labor room regarding different Gynae \& Obstetrical problems with 13 to 15 deliveries being conducted on daily basis.

\section{Ethical consideration}

A verbal consent was taken from all participants prior to the survey. The collected information was kept confidential. Furthermore, study was reviewed by hospital review committee.

\section{Inclusion criteria}

1) Voluntariness was required for the survey of knowledge.

2) Participant was enrolled with age 15 years and above.

3) Completed questionnaire were included.

\section{Exclusion criteria}

1) Respondents with age less than 15 years.

2) Failing to provide with consent.

3) Incomplete questionnaires.

\section{Sampling technique}

Convenient sampling technique was used to explore the perception among the pregnant women regarding CS in Gynae unit of Women and Children Teaching Hospital Bannu.

\section{Sample size calculation}

The sample size was determined by using the sample size calculator at Raosoft ${ }^{\circledR}$ web site [17], being ensured that the minimum number of respondents represented maximum population of District Bannu. The parameters given consideration in the sample size calculation included indicator percentage, margin of error, confidence level, population size and critical value for the confidence level in this study. The indicator percentage was assumed (0.50) with the confidence level of $95 \%$. The amount of admissible error i.e. margin of error was kept (5\%), which requires a larger sample size.

After calculating the sample size the minimum sample size required was 377 and the participants were to participate in order to achieve $95 \%$ of confidence level in our study. In current study a total of 402 respondents were surveyed to make the results more accurate and to provide maximum opportunity for the general people to participate in the study.

A self-administered questionnaire was used to collect the data from the pregnant women and to evaluate people's perception on CS. The questionnaire was designed on the basis of literature survey carried out for knowledge and perception of patients regarding CS [4,9,11,13] Validation of the questionnaire was done on 30 pregnant women which resulted in Cronbach`s Alpha of (0.73).

The interviewer sought the personal perception of the clients about CS using four grades: very bad, bad, good, very good, as shown in table 1. The clients' general perceptions related to CS were also explored and the communications were made into local language by nursing staff co-operation. The data obtained was entered and analyzed using the Statistical Package for Social Sciences version 16.0 (SPSS In., Chicago, IL, USA).

\section{Results}

Of 450 questionnaires administered, 402 were fully completed and were included in this analysis. Mean age of all respondents was $27.2 \pm$ 4.0 years that ranged between 16 and 44 years.

Among the study population, 41 (10.2\%) had a previous history of CS, 97 (24.1\%) had delivered at least once by the vaginal route and 41 (10.2\%) were nulliparous. Out of the 41 women with a CS in the past, $36(87.8 \%)$ were favorably received at home following the CS, while $5(12.2 \%)$ patients did not have good reception at home from their relatives.

Table 1 reveals views of pregnant women regarding CS during the current pregnancy period. It shows that CS was considered very bad by 195 (48.6\%) women, whereas only 71 (17.6\%) of the women viewed CS as positive procedure either for themselves or the baby. Seven (1.7\%) participants viewed CS as very good and elected to undergo CS to avoid the labor pain and complications of delivery. Meanwhile, 129 (32.1\%) respondents considered CS as a negative procedure and were reluctant to undergo the procedure, ever if the doctors thought it was necessary to save their lives or their baby. Three respondents viewed CS as being very bad and did not want to undergo CS at any cost.

Table 2 reflects the cultural perception of the respondents about CS. Out of 402 participants, 267 (66.4\%) indicated CS as a normal

\begin{tabular}{|c|c|c|c|}
\hline Views & Description of Views & Number & Percentage \\
\hline Very Good & $\begin{array}{c}\text { Will accept CS by choice to avoid the } \\
\text { complications of labor }\end{array}$ & 7 & 1.7 \\
\hline Good & $\begin{array}{c}\text { Will accept CS in case of threat to their } \\
\text { lives }\end{array}$ & 71 & 17.6 \\
\hline Bad & $\begin{array}{c}\text { Will reluctantly accept CS if the doctors } \\
\text { communicate \& convenes }\end{array}$ & 129 & 32.1 \\
\hline Very Bad & $\begin{array}{c}\text { Will not accept CS under any of the } \\
\text { above circumstances }\end{array}$ & 195 & 48.6 \\
\hline Total & & 402 & 100 \\
\hline
\end{tabular}

Table 1: Views about Cesarean Section (CS) in their Index Pregnancy.

\begin{tabular}{|l|l|l|}
\hline Perception & Number & Percentage \\
\hline Normal obstetric decision & 267 & 66.4 \\
\hline Women with abnormal pelvis & 63 & 15.6 \\
\hline Women who are obstetric failure & 37 & 9.2 \\
\hline CS strongly disliked OR even Cursed women & 35 & 8.7 \\
\hline Total & 402 & 100 \\
\hline
\end{tabular}

Table 2: Cultural Perception about Cesarean Section. 


\begin{tabular}{|l|l|l|}
\hline Fear & Number & Percentage \\
\hline Fear of Death & 145 & 36.1 \\
\hline No Fear & 124 & 30.9 \\
\hline Fear of postoperative pain & 93 & 23.1 \\
\hline Fear of subsequent infertility & 26 & 6.5 \\
\hline Fear of Doctor's incompetency & 14 & 3.4 \\
\hline Total & 402 & 100 \\
\hline
\end{tabular}

Table 3: Fears of Antenatal Clients about Cesarean Section.

obstetric decision while 37 (9.2\%) viewed CS as the woman's failure of her obstetric responsibility. Only $35(8.7 \%)$ women strongly disliked and/or even reported their culture i.e. CS being a curse for women.

Majority of the respondents (145 (36.1\%)) were afraid of death as a complication of CS while $93(23.1 \%)$ were terrified from the postoperative pain associated with CS. However, notable number of respondents $(30.9 \%)$ did not have any fear about CS. Some of the patients were frightened by subsequent infertility. Table 3 shows the expression of the study group's fear about CS.

\section{Discussion}

Vaginal birth has been considered safer but painfull way of delivery throughout the history [18]. Women's health is a great challange especially in developing nations where awareness is very limited. While perceptions are getting changed with scientific and research advancement, awareness in same scenario depicts huge difference in developed and developing country. Delivery is a natural procedure in majority of women, while the maternal mortality in this area was 204/100,000 [19]. In new era, CS reasonably safer in selected women as shown in present study.

Current study shows that 129 (32.1\%) of the study population was not favorably disposed to CS. The respondents unwillingly agreed to have a CS only after doctor's referral or responded not to accept it at all, otherwise. Current findings show slightly higher rate than reported from Nigeria, where $11.6 \%$ of patients rejected CS in a tertiary level hospital and $12.1 \%$ of women did not accept CS under any circumstances [8]. Only $7(1.7 \%)$ were reported to be willing to accept CS as a method of delivery to avoid the pains of labor and complications of delivery. Moreover, 71 (17.6\%) would only accept CS if needed to save their lives or that of their babies without any other option. Such findings are in pipeline with published literature either from developed country or developing country $[4-7,20]$.

The number of women that unfavorably disposed to CS was significant. It provided an insight of the factors responsible for the unacceptably high maternal and perinatal mortality ratio. It may seem similar to the trend and factors observed in Nigeria i.e. type one delay in accessing formal obstetric care [21]. Furthermore, fear of CS was also one of the most common hindrance for which women proffered utilizing formal maternity services [16]. This offers an explanation for women presenting late to the center with complications, resulting in an unacceptably high mortality ratio.

The major concern expressed by the respondents in present study was the fear of death during the procedure. This was found a genuine concern considering the high rate of maternal death associated with CS in African countries like Nigeria [22]. The other concerns of the respondents include fear of error during the surgery, fear of subsequent infertility and postoperative pain. These also were notable fears as postoperative pain, infertility, and iatrogenic fistula are complications that can follow CS.
Significant (33.6\%) respondents indicated negative cultural perception of their communities about CS. The CS was perceived by respondents as a procedure carried out on unfaithful and cursed women as well as women who were viewed as weaklings. As the observed trend is a great reluctance among women and their relations to accept the procedure, cultural perception of the individual communities is vital to the acceptance of the procedure. Such cultural perception may possibly "partly explain" why the number of women who booked for antenatal care in the center is significantly different from the actual number who delivered in the center. Some clients may choose to deliver at home or with a maternity center after receiving antenatal care in the center because of fear for CS. The study further shows that clients who have had a previous CS would have had some of their fears about the procedure either confirmed or disabused; thus, they are likely to have a more informed view of the procedure than those who were yet to have their fears tested.

About $10.2 \%$ of the study population had a previous history of CS and $36(87.8 \%)$ patients of this group were favorable while $12.2 \%$ were not well received at home following the procedure. The negative reception at home from family and community members may negatively affect the client's acceptance of a CS in the index pregnancy may be a valid factor adversely affecting maternal and perinatal outcome.

\section{Conclusions}

Current study strengthens the fact that significant proportion of antenatal clients are reluctant to CS with negative cultural perception as a reinforced hatred. The intolerable maternal mortality rate $(204 / 100,000)$ in Bannu and or these areas of Pakistan may partly be attributable to type one delay in accessing formal maternity services. This however, may be related to the fear of CS which earlier studies have also documented as a cause of underutilization of formal maternity services. The concerns and doubts expressed by the patients should be addressed to improve underprivileged utilization of health services for delivery. Moreover, proper programs to modify the negative perception of the local population about CS should also be adopted. These measures will ensure reduction in type one delay to a more tolerable level and accordingly, reduction in maternal mortality.

\section{Limitation of the Study}

There are some limitations of the study like social, cultural and economic status of women.

\section{References}

1. Bamigboye AA, Hofmeyr GJ (2005) Non-closure of peritoneal surfaces at caesarean section--a systematic review. S Afr Med J 95: 123-126.

2. Jaiyesimi RA, Ojo OE (2003) Caesarean section. In: contemporary Obstetrics and Gynecology for developing countries. Okonufua EF, Kunle O (eds.). Nigeria: Women's Health and Action Research centre Benin City 592-619.

3. Rosalie M Grivell, Jodie M Dodd (2011) Short- and Long-term Outcomes after Cesarean Section. Expert Rev of Obstet Gynecol 6: 205-215.

4. Martin JA, Hamilton BE, Sutton PD, Ventura JS, Menacker F, et al. (2009) Births: final data for 2006. Natl Vital Stat Rep 58: 71-85.

5. Method of delivery, 1980 to 2007-8. In: The Information Centre. National Health Services, UK (2009)

6. Zeitlin J, Mohangoo A (2004) European Perinatal Health Report - data from 2004. EURO-PERISTAT project.

7. Department of Health, Taiwan: Birth registry 2008.

8. Cynthia KS, Sara AH (2006) Levels and Trends in Caesarean Birth in the Developing World. Studies in Family Planning 37: 41-48. 
Citation: Qazi Q, Akhtar Z, Khan K, Khan AH (2013) Pregnant Women View Regarding Cesarean Section in Northwest Pakistan. Trop Med Surg 1: 105. doi:10.4172/2329-9088.1000105

Page 4 of 4

9. Kwawukuma EY (2001) Caesarean section in Developing countries. Best pract Res Clin Obstet Gynaecol 15: 165-178.

10. Buekens P, Curtis S, Alayon S (2003) Demographic and Health surveys: Caesarean section rates in sub-Saharan Africa. BMJ 326: 136.

11. Okonufua F (2001) Optimising Caesarean section rates in West Africa. Lance 358: 1289

12. Lumbiganon P, Laopaiboon M, GülmezogluAM, Paulo Souza J, Taneepanichskul S, et al. (2010) Method of delivery and pregnancy outcomes in Asia: the WHO global survey on maternal and perinatal health 2007-08. Lancet 375: 490-499.

13. Naithani U, Bharwal P, Chauhan SS, Kumar D, Gupta S, et al. (2011) Knowledge, attitude and acceptance of antenatal women toward labor analgesia and caesarean section in a medical college hospital in India. J Obstet Anaesth Crit Care 1: 13-20.

14. Lin HC, Xirasagar S (2004) Institutional factors in caesarean delivery rates: policy and research implications. Obstet Gynecol 103: 128-136.

15. Pai M (2000) Unnecessary Medical Interventions: Caesarean Sections as a Case Study. Economic and Political Weekly 35: 2755-27561.
16. Office of Executive District Health Officer, District Bannu; Department of Health Khyber Pakhtunkhwa, Pakistan

17. http://www.raosoft.com/samplesize.htm

18. Syeda Rabia, Rumina Tabassum (2010) Maternal outcome in cases of vaginal deliveries after one Cesarean section. Pak J Surg 26: 237-241.

19. Musarrat Jabeen, Fouzia Gul, Muhammad Rahman (2005) Maternal mortality ratio and its causes in a district headquarter hospital of NWFP. JPMI 19: 45-51.

20. Behague DP, Victora CG, Barros FC (2002) Consumer demand for caesarean sections in Brazil: informed decision making, patient choice, or social inequality? A population based birth cohort study linking ethnographic and epidemiologica methods. BMJ 324: 942-945.

21. Ozumba BC, Anya SE (2002) Maternal deaths associated with Cesarean section in Enugu, Nigeria. Int J Gynecol Obstet 76: 307-309.

22. Arulkumaran S (2007) Obstetric Proceeding in Dewhurst's Textbook of Obstetrics and Gynecology. In: Keith D (ed.). (7thedn), United States: Edmonds Blackwell publishing 547-51. 